CLINICAL STUDY

\title{
Evaluation of insulin sensitivity with a new lipid-based index in non-diabetic postmenopausal overweight and obese women before and after a weight loss intervention
}

\author{
Barbara Antuna-Puente ${ }^{1,2, *}$, Emmanuel Disse ${ }^{3, *}$, May Faraj $^{4,5}$, Marie-Eve Lavoie ${ }^{4}$, Martine Laville $^{3}$, \\ Rémi Rabasa-Lhoret ${ }^{4,5,6}$ and Jean-Philippe Bastard ${ }^{1,2,7}$ \\ ${ }^{1}$ Inserm, CDR 893, équipe 7, Paris F-75012, France, ${ }^{2}$ Université Pierre et Marie Curie-Paris 6, Faculté de Médecine, UMRS680, Paris F-75005, France, \\ ${ }^{3}$ Centre de Recherche en Nutrition Humaine Rhône-Alpes, Université Claude Bernard Lyon1, Hospices Civils de Lyon, Lyon, France, ${ }^{4}$ Department of \\ Nutrition, Université de Montréal, Montréal, Québec, Canada, ${ }^{5}$ Institut de Recherches Cliniques de Montréal, Montréal, Québec, Canada, ${ }^{6}$ Centre de \\ Recherche sur le Diabète de Montréal (MDRC), Centre de Recherche du Centre Hospitalier de L’Université de Montréal, Montréal, Québec, Canada and \\ ${ }^{7}$ AP-HP, Hôpital Hôpital Tenon, Service de Biochimie et Hormonologie, Paris F-75020, France \\ (Correspondence should be addressed to R Rabasa-Lhoret at Institut de Recherches Cliniques de Montréal; Email: remi.rabasa-Ihoret@ircm.qc.ca)
}

*(B Antuna-Puente and E Disse contributed equally to this work)

\begin{abstract}
Objective: To evaluate the validity of a new lipid-based index (Disse index) in assessing insulin sensitivity (IS) compared with the hyperinsulinemic-euglycemic (HIEG) clamp in overweight and obese, nondiabetic, postmenopausal women, before and after a weight loss intervention.

Research design and methods: Association between Disse index and the HIEG clamp was evaluated in 86 non-diabetic postmenopausal overweight and obese women before and after weight loss. Percentage changes $(\% \Delta)$ were calculated for several fasting indices and compared with $\% \Delta$ of HIEG clamp.

Results: We observed a strong correlation between Disse index and HIEG clamp $(r=0.69, P<0.001)$. This association was higher than those of homeostasis model assessment (HOMA), quantitative insulin sensitivity check index (QUICKI), and McAuley indices while no significant difference was observed with Revised-QUICKI. Percent change of Disse index (pre- versus post-weight loss program) was significantly correlated with $\% \Delta$ of HIEG clamp $(r=0.34, P<0.01)$. This correlation was similar to those observed for the other indices tested.

Conclusions: We validated the reliability of Disse index in assessing IS in non-diabetic post-menopausal overweight and obese women, before and after weight loss intervention. Disse index may be useful not only for insulin resistant diagnostics in this type of population, but also for the IS follow-up after a weight-loss program and weight stabilization. The presence of lipid elements in this fasting index improves the estimation of IS in overweight and obese non-diabetic post-menopausal women and could add more information about peripheral IS.
\end{abstract}

European Journal of Endocrinology 161 51-56

\section{Introduction}

Simultaneous and coordinated function of pancreatic $\beta$-cells, liver, and peripheral tissues, mainly muscles, maintain the normal glucose homeostasis (1). The hyperinsulinemic-euglycemic (HIEG) clamp is the reference method of insulin sensitivity (IS) measurement (2); however, it is costly and technically demanding. To simplify this, several surrogate indices for IS assessment have been developed using glucose and insulin at fasting levels. The validity of these indices relies on how well they correlate with IS measured by the HIEG clamp. Presently, HOMA index is the most widely used followed by QUICKI and both have been broadly evaluated. However, they were less effective in healthy than in insulin resistant populations (3).
For this reason, several groups have developed different formulas with additional metabolic markers to assess IS. McAuley et al. observed that the variables that best predicted IS were fasting insulin and fasting triglycerides in a population of 178 normoglycemic individuals, thus the use of triglycerides and insulin in the formula resulted in a higher sensitivity in predicting IS (4). Similarly, Perseghin et al. demonstrated that incorporating non-esterified fatty acids (NEFA) to the QUICKI equation improved its association with the HIEG in nonobese subjects (5). This was further confirmed by Rabasa-Lhoret et al. in a large population with a wide IS range, where Revised-QUICKI was better correlated to HIEG clamp, which means that it would be suitable for population screening (6). 
More recently, we developed a new fasting index for IS assessment in a population of 70 ( 31 men, 39 women) French normoglycaemic, non-obese individuals, which takes into account fasting levels of high density lipoprotein (HDL) cholesterol, total cholesterol, and NEFA (Table 1) (7). We observed a higher correlation between the clamp and Disse index $(r=0.79$, $P<0.0001)$ in this healthy population, compared with other fasting indices, including HOMA and QUICKI indices $(r=-0.52, r=0.52, P \leq 0.0001$ respectively) (7).

Menopause transition is associated with body fat redistribution, with a preferential accumulation of abdominal adipose tissue, which is related to an increased risk of cardiovascular and metabolic diseases $(8,9)$. As decreased IS is one major contributor to this and is commonly present in this population, it is important to make an early detection and quantification of insulin resistance. Therefore, the aim of the present study was to evaluate the validity of this new lipid-based index, Disse index, in assessing IS compared with the HIEG clamp in a risk population of non-diabetic postmenopausal obese and overweight women, both before and after a 6-month weight loss program.

\section{Research design and methods}

We performed the correlation analysis in non-diabetic postmenopausal overweight and obese women subjects recruited for a weight-loss study by the Montreal Ottawa New Emerging Team (MONET) in the Department of Nutrition, Université de Montréal (10-12). The cohort included 137 women who were weight stable for 2 months prior to the study and met the following criteria: i) body mass index (BMI) more than $27 \mathrm{~kg} / \mathrm{m}^{2}$, ii) cessation of menstruation for more than 1 year and a FSH level of more than or equal to $30 \mathrm{U} / \mathrm{l}$, iii) sedentary $(<2 \mathrm{~h} /$ week of structured exercise), iv) non-smokers, v) low to moderate alcohol consumers (less than two drinks per day), vi) free of known inflammatory disease, and vii) no use of hormone replacement therapy within the last 3 months. All participants had no history or evidence of the following: i) cardiovascular disease, peripheral vascular disease or stroke, ii) diabetes $(2 \mathrm{~h}$ plasma glucose $<11.0 \mathrm{mmol} / \mathrm{l}$ after a $75 \mathrm{~g}$ oral glucose tolerance test), iii) body weight fluctuation $\pm 2 \mathrm{~kg}$ in the last 6 months, iv) thyroid or pituitary disease, v) infection by medical questionnaire examination and complete blood count, and vi) taking medication that could affect cardiovascular function and/or metabolism. Additionally, the subjects did not have evidence of polycystic ovary syndrome, which could affect the relation between the HIEG clamp and the surrogate's indices (13). The study was approved by the Université de Montréal Ethics Committee. After reading and signing the consent form, each participant was submitted to a series of tests.

Subjects underwent a weight loss intervention for 6 months induced by a hypocaloric diet (1100$1800 \mathrm{kcal}$ with an energy deficit of 500-800 kcal/day) with or without resistance training. Out of the 137 subjects, 107 women completed the study, from which 84 women had complete data sets of the required parameters. Subjects underwent a HIEG clamp (insulin infusion rate: $75 \mathrm{mU} / \mathrm{m}^{2}$ per $\mathrm{min}$ ) for $180 \mathrm{~min}$ as previously described (10-12) before and after weight loss. Glucose disposal rate (M; milligrams per minute per kilogram of free fat mass) was calculated from measurements taken during the final $30 \mathrm{~min}$ of the clamp. IS was expressed as the ratio of $\mathrm{M}$ corrected by fat-free mass (Mffm) over insulin ( $\mathrm{Mffm} / \mathrm{I})$. Fasting serum insulin (RIA, Medicorp, Montreal, Canada), NEFA (NEFAC test, Wako Chemicals, Richmond, VA, USA), glucose, total cholesterol, HDL cholesterol, and triglycerides (COBAS INTEGRA 400, Roche Diagnostics) were measured before and after weight loss as previously described (10-12). All measurements were conducted following a period of 1 month of supervised weight stability (variation within $2 \mathrm{~kg}$ ). Free fat mass was evaluated by dual-energy X-ray absorptiometry (version 6.10.019 General Electric Lunar Corporation, Madison, WI, USA). Fasting-derived IS indices were calculated as previously published (Table $1 ; 3-5,7,14$ ).

\section{Statistical analysis}

Statistical differences between clinical and metabolic characteristics before and after weight loss were assessed by the Wilcoxon rank test. Percentage change of each index and of $\mathrm{Mffm} / \mathrm{I}$ was calculated as $\% \Delta=(($ value after weight loss $\times 100) /$ value before weigh loss)-100). Spearman correlation coefficient was calculated to express the strength of the relationship between the simple fasting indices and $\mathrm{Mffm} / \mathrm{I}$. Comparison of correlations was made using the

Table 1 Indices of insulin sensitivity derived from fasting measurements.

\begin{tabular}{lll}
\hline Fasting index & Formula & Reference \\
\hline HOMA & $($ (glucose $) \times($ insulin) $) / 22.5$ & $(14)$ \\
QUICKI & $1 /(\log ($ glucose $)+\log ($ insulin $))$ & $(3)$ \\
Revised-QUICKI & $1 /(\log ($ glucose $)+\log ($ insulin $)+\log ($ NEFA $))$ & $(5)$ \\
McAuley & exp $(2.63-0.28$ In(insulin) -0.31 In(triglycerides $))$ & $(4)$ \\
Disse & $12 \times((2.5 \times(\mathrm{HDL}-$ total cholesterol $)-N E F A)-$ insulin $)$ & $(7)$ \\
\hline
\end{tabular}

NEFA, non-esterified fatty acids. 
method described in Dawson \& Trapp (15) as follows: $t=\left(r_{\mathrm{xy}}-r_{\mathrm{xz}}\right) \sqrt{ }(n-3)\left(1+r_{\mathrm{yz}}\right) / 2\left(1-r_{\mathrm{xy}}^{2}-r_{\mathrm{xz}}^{2}-r_{\mathrm{yz}}^{2}+2 r_{\mathrm{xy}}\right.$ $\left.r_{\mathrm{xz}} r_{\mathrm{yz}}\right)$, where $r_{\mathrm{xy}}$ is the correlation between one index (i.e. Disse) and the HIEG clamp, $r_{\mathrm{Xz}}$ is the correlation between another fasting index (i.e. HOMA) and the HIEG clamp and $r_{\mathrm{yz}}$ is the correlation between the two compared fasting indices. The Bland-Altman plot was used to assess the agreement between $\mathrm{Mffm} / \mathrm{I}$ and fasting IS indices. The threshold for significance was set at $P=0.05$.

\section{Results}

Characteristics of subjects before and after weight loss are presented in Table 2 as well as measures of insulin action. Mean age was 58.1 years (s.e.M. \pm 0.5$)$, only two patients were under the age of 50 (46 years old). Table 3 shows the correlation coefficient between HIEG clamp and each of the fasting-based indices, before and after weight loss in the whole population and in the overweight and obese subgroups. The association between $\mathrm{Mffm} / \mathrm{I}$ and the different indices was statistically significant in the whole study population. However, Disse index showed a higher association with Mffm/I than HOMA, QUICKI, and McAuley $(P<0.05)$ by using the comparison test between correlations (15). No significant difference was observed with Revised-QUICKI $(P=0.17)$.

Bland-Altman plots showed the good agreement between Mffm/I and Disse index, Revised QUICKI, HOMA, and QUICKI, demonstrating that $<6 \%$ were outside 1.96 S.D. for Disse index and Revised QUICKI (Fig. 1) and $<7 \%$ for HOMA and QUICKI (data not shown).

When the population was divided into overweight $\left(\mathrm{BMI}=25-30 \mathrm{~kg} / \mathrm{m}^{2}\right)$ and obese $\left(\mathrm{BMI}>30 \mathrm{~kg} / \mathrm{m}^{2}\right) \mathrm{sub}-$ groups, we observed a strong association between
Mffm/I and Disse index in obese subjects, although it was not statistically different to other fasting indices used, except for McAuley $(P<0.05)$. As for the overweight group, we observed similar associations between $\mathrm{Mffm} / \mathrm{I}$ and the different indices. Disse index yielded a consistent relationship with $\mathrm{Mffm} / \mathrm{I}$ after weight loss in all subjects (Table 3).

The percent changes of Disse index was significantly correlated with $\% \Delta$ of $\mathrm{Mffm} / \mathrm{I}(r=0.34, P<0.01)$. This correlation was similar to those observed for the other indices (data not shown).

\section{Discussion}

Fasting-based indices offer important advantages in estimating IS as they are obtained from few fasting blood samples and are well correlated with HIEG clamp in different populations $(3,14)$. Despite their practicality in estimating IS in large cohorts, it was shown that fasting indices using glucose and insulin values represent hepatic rather than peripheral insulin resistance (16-18). In an effort to improve the effectiveness of these simple indices, new mathematical models have been described using additional variables (4-5). Recently, we developed a new fasting index of IS in a non-obese population that incorporates the lipid profile in its calculation (7) and was highly related to HIEG clamp even if it does not include glucose value in its calculation (7) like most surrogate fasting indices.

To be widely used, any measurement method should show a good correlation with the gold standard in any population. This is also the case for fasting indices, as different populations have different metabolic profiles and their performance could vary from one to another. Indeed, the existing fasting indices, like HOMA-IR, QUICKI, and revised QUICKI have been validated in different studies in distinct populations with different

Table 2 Clinical and metabolic characteristics of the whole study population.

\begin{tabular}{|c|c|c|c|}
\hline & Before weight loss & After weight loss & $P$ \\
\hline Age & $58.08 \pm 0.51$ & - & \\
\hline $\mathrm{BMI}\left(\mathrm{kg} / \mathrm{m}^{2}\right)$ & $32.56 \pm 0.50$ & $30.49 \pm 0.52$ & $<0.001$ \\
\hline Fat mass $(\mathrm{kg})$ & $39.00 \pm 0.99$ & $34.51 \pm 1.10$ & $<0.001$ \\
\hline Free fat mass $(\mathrm{kg})$ & $45.74 \pm 0.75$ & $44.85 \pm 0.64$ & $<0.01$ \\
\hline Total cholesterol (mmol/l) & $5.41 \pm 0.10$ & $5.37 \pm 0.10$ & NS \\
\hline HDL cholesterol (mmol/l) & $1.44 \pm 0.03$ & $1.41 \pm 0.03$ & NS \\
\hline LDL cholesterol $(\mathrm{mmol} / \mathrm{l})$ & $3.19 \pm 0.09$ & $3.25 \pm 0.09$ & NS \\
\hline Triglycerides (g/l) & $1.70 \pm 0.08$ & $1.55 \pm 0.09$ & $<0.01$ \\
\hline NEFA $(\mathrm{mmol} / \mathrm{l})$ & $0.650 \pm 0.023$ & $0.635 \pm 0.019$ & NS \\
\hline Fasting glucose $(\mathrm{mmol} / \mathrm{l})$ & $5.16 \pm 0.06$ & $5.15 \pm 0.06$ & NS \\
\hline Fasting insulin $(\mu \mathrm{Ul} / \mathrm{ml})$ & $15.56 \pm 0.68$ & $13.70 \pm 0.64$ & $<0.001$ \\
\hline $\mathrm{Mffm} / \mathrm{I}$ & $5.64 \pm 0.21$ & $6.23 \pm 0.19$ & $<0.01$ \\
\hline HOMA & $3.60 \pm 0.17$ & $3.16 \pm 0.16$ & $<0.001$ \\
\hline QUICKI & $0.321 \pm 0.002$ & $0.327 \pm 0.002$ & $<0.001$ \\
\hline Revised-QUICKI & $0.345 \pm 0.003$ & $0.353 \pm 0.003$ & $<0.01$ \\
\hline McAuley & $7.74 \pm 0.12$ & $8.00 \pm 0.12$ & $<0.01$ \\
\hline Disse & $-15.20 \pm 0.81$ & $-13.28 \pm 0.75$ & $<0.01$ \\
\hline
\end{tabular}

Data are means and \pm S.E.M.; BMI, body mass index; NEFA, non-esterified fatty acids; Mffm/l, measured as mg/min per kg of free fat mass; NS, not significant. 
Table 3 Spearman correlation coefficients between fasting-based indices of insulin sensitivity and Mffm/l, before and after weight loss.

\begin{tabular}{|c|c|c|c|c|c|c|}
\hline & \multicolumn{2}{|c|}{$\begin{array}{l}\text { Whole study population } \\
\qquad n=86\end{array}$} & \multicolumn{2}{|c|}{$\begin{array}{c}\text { Obese } \\
\left(\geq 30 \mathrm{~kg} / \mathrm{m}^{2}\right) n=53\end{array}$} & \multicolumn{2}{|c|}{$\begin{array}{c}\text { Overweight } \\
\left(25-30 \mathrm{~kg} / \mathrm{m}^{2}\right) n=33\end{array}$} \\
\hline & Before & After & Before & After & Before & After \\
\hline Disse & $0.69^{\ddagger}$ & $0.54^{\ddagger}$ & $0.72^{\ddagger}$ & $0.58^{\ddagger}$ & $0.56^{\dagger}$ & $0.46^{\dagger}$ \\
\hline HOMA & $-0.60^{\ddagger}$ & $-0.50^{\ddagger}$ & $-0.64^{\ddagger}$ & $-0.54^{\ddagger}$ & $-0.43^{\star}$ & $-0.46^{\dagger}$ \\
\hline QUICKI & $0.60^{\ddagger}$ & $0.50^{\ddagger}$ & $0.64^{\ddagger}$ & $0.54^{\ddagger}$ & $0.43^{*}$ & $0.46^{\dagger}$ \\
\hline Revised-QUICKI & $0.67^{\ddagger}$ & $0.46^{\ddagger}$ & $0.67^{\ddagger}$ & $0.47^{\ddagger}$ & $0.60^{\ddagger}$ & $0.42^{*}$ \\
\hline McAuley & $0.42^{\ddagger}$ & $0.22^{*}$ & $0.44^{\ddagger}$ & 0.23 & $0.40^{*}$ & 0.13 \\
\hline
\end{tabular}

${ }^{\star} P<0.05 ;{ }^{\dagger} P<0.01 ;{ }^{\ddagger} P<0.001$.

glucose tolerance and various levels of IS, though the performance of each index was different depending on the type of population considered $(3,5,6,14,16,19)$. In this study, we confirmed the good correlation between the Disse index and the HIEG clamp in a Canadian population of non-diabetic post-menopausal overweight and obese population, as was previously observed in a French population of normoglycemic nonobese subjects (7).
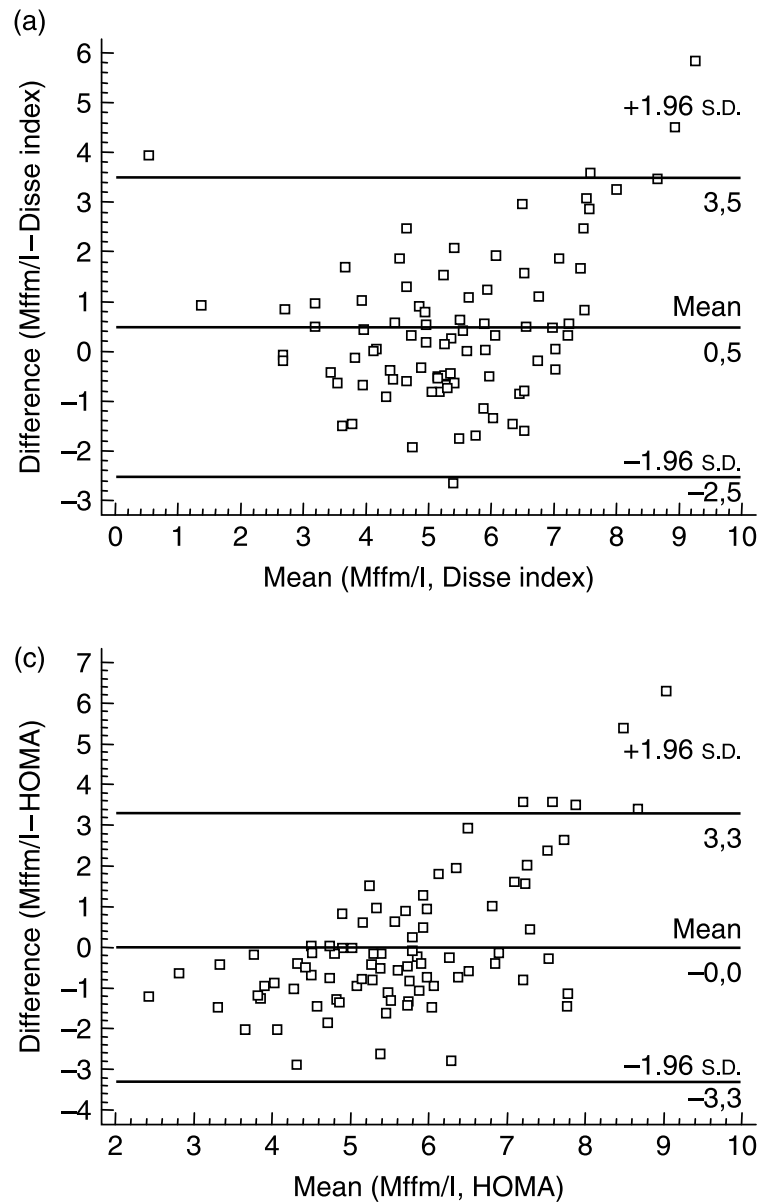

In addition to an accurate estimation of IS, it is essential that an index closely track variation of this parameter. Compared to other surrogate indices, Disse index showed a good correlation with the clamp before and after weight loss intervention. The Bland-Altman plot (Fig. 1) showed $<6 \%$ of disagreement between Disse index and the clamp HIEG before weight loss, with a good agreement after weight loss $(<4 \%$ of disagreement, data not shown). In addition, the \% of change of
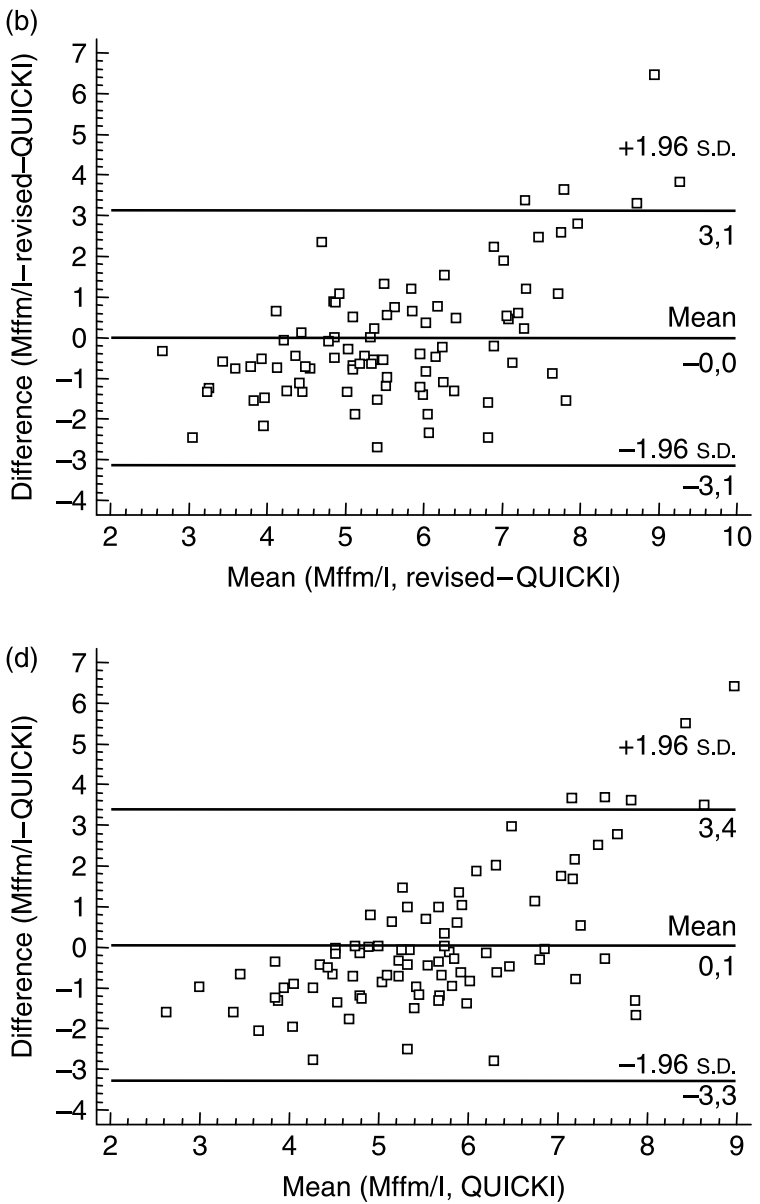

Figure 1 Bland-Altman plot for insulin sensitivity as assessed by the hyperinsulinemic-euglycaemic clamp and: a) Disse index, b) RevisedQUICKI, c) HOMA, and d) QUICKI. The clamp-to-different index is plotted against the mean measured values of insulin sensitivity from the clamp and the indices, and reveals good agreement between the measurement methods. 
Disse index showed a significant correlation to \% of change of the HIEG clamp, to a similar extent as that previously reported for QUICKI in a type 2 diabetes mellitus HIEG clamp study, before and after a diet and exercise intervention (19). All these results suggest that Disse index could be useful for IS follow-up during a weight loss intervention. It is important to note that the measurement of NEFA was done after a period of stable weight, as we and others previously reported that NEFA levels affected surrogate indices results during weight loss because they reflected mainly lipolysis induced by diet rather than resistance to the anti-lipolytic effect of insulin $(20,21)$.

It is interesting to note that among the fasting indices tested, Disse index and Revised QUICKI, which incorporate circulating NEFA in their formulas, showed the highest association with the clamp before weight loss. As previously reported in several trials performed in adults, we obtained a better estimation of whole body IS by adding NEFA in fasting formulas as an indirect measure of the anti-lipolytic effect of insulin than when only glucose and insulin measures are taken into account $(5,6,22,23)$. Indeed, increased lipolysis characterized by high plasma levels of NEFA is a common feature of an early peripheral insulin resistance (24). However, the use of NEFA in a simple index has a pre-analytical limitation related to determination of NEFA plasma levels. To prevent in vitro lipolysis that could provoke a false high result, samples need to be centrifuged or an anti-lipolytic drug needs to be added, soon after they are taken (25). Neither of these two solutions is convenient on a large scale scenario like clinical practice. To have a collection tube with the antilipolysis product all ready to use could solve this problem.

It has been shown that age could affect IS (26). However, in a population of obese post-menopausal women, Ozbey and co-workers (27) showed no difference in HOMA and fasting insulin between older $(>50$ years old) and younger ( $<50$ years old) women. In addition, age might not be considered as a confounding factor in the present study since the population was homogeneous for age, (mean age was 58.1 in obese and overweight subjects), and only two subjects were $<50$ years (46 years old).

IS could also differ substantially between overweight, obese, and type 2 diabetic individuals $(28,29)$. In the case of postmenopausal women, fat redistribution and more particularly increased visceral fat is related to increased insulin resistance and high NEFA circulating levels (30, 31 ). This could affect the performance of fasting indices as previously reported $(3,6)$. Therefore, we divided the population into overweight and obese subgroups in order to assess whether these correlations were affected by the degree of adiposity. Correlations between the surrogate indices and the HIEG clamp were similar between the obese group and the whole population. Although the relationship between the HIEG clamp and surrogate indices was weaker in individuals with lower BMI $(3,6$, 28), Disse index showed a good association with the HIEG clamp in overweight subjects, suggesting that it is reliable in both overweight and obese women and is able to diagnose insulin resistance in a wide range of nondiabetic women.

In conclusion, we validated the reliability of new Disse index in post-menopausal non-diabetic overweight and obese women and demonstrated its efficiency after a weight-loss intervention. Disse index may be useful not only for insulin resistant diagnostics but also for the IS follow-up after a weight-loss program. The presence of lipid profile elements in Disse index improves the estimation of IS in non-diabetic adult subjects. It also could give more information about peripheral IS and may be of particular interest to identify insulin resistant subjects (7). Further studies need to be performed to assess Disse index efficiency in populations with different IS levels like polycystic ovary syndrome and type 2 diabetes mellitus. Also, future studies should address the influence of lipid disorders and lipidlowering treatment on the effectiveness of Disse index in assessing IS in dyslipidemia.

\section{Declaration of interest}

The authors declare that there is no conflict of interest that would prejudice the impartiality of this scientific work.

\section{Funding}

This work is part of the Montreal-Ottawa New Emerging Team (MONET) in Obesity and is supported by grants from the Canadian Institute of Health Research (CIHR) \# OHN-63279 as well as grant \# MOP-62976. M Faraj is a recipient of the CIHR New Investigator Award and R Rabasa-Lhoret and M E Lavoie are supported by a fellowship from the Fonds de Recherche en Santé du Québec (FRSQ). $\mathrm{R}$ Rabasa-Lhoret also received funding as J-A DeSeve Chair in clinical research. B Antuna-Puente is supported by a PhD, scholarship from CONACYT.

\section{References}

1 DeFronzo RA. Lilly lecture 1987: the triumvirate: beta-cell, muscle, liver. Collusion responsible for NIDDM. Diabetes 198837 667-687.

2 DeFronzo RA, Tobin JD \& Andreas R. Glucose clamp technique: a method for quantifying insulin secretion and resistance. American Journal of Physiology 197985 E214-E223.

3 Katz A, Nambi SS, Mather K, Baron AD, Follmann DA, Sullivan G \& Quon MJ. Quantitative insulin sensitivity check index: a simple, accurate method for assessing insulin sensitivity in humans. Journal of Clinical Endocrinology and Metabolism $2000 \mathbf{8 5}$ 2402-2410.

4 McAuley K, Williams S, Mann J, Walker R, Lewis-Barned N, Temple L \& Duncan A. Diagnosing insulin resistance in the general population. Diabetes Care 200124 460-464.

5 Perseghin G, Caumo A, Caloni M, Testolin G \& Luzi L. Incorporation of the fasting plasma FFA concentration into QUICKI improves its association with insulin sensitivity in nonobese individuals. Journal of Clinical Endocrinology and Metabolism $2001864776-4781$.

6 Rabasa-Lhoret R, Bastard JP, Jan V, Ducluzeau PH, Andreelli F, Guebre F, Bruezau J, Louche-Pellissier C, Mitrepierre C, Peyrat J, Chagne J, Vidal H \& Laville M. Modified quantitative insulin 
sensitivity check index is better correlated to hyperinsulinemic glucose clamp than other fasting-based index of insulin sensitivity in different insulin-resistant states. Journal of Clinical Endocrinology and Metabolism $2003 \mathbf{8 8} 4917-4923$.

7 Disse E, Bastard JP, Bonnet F, Maitrepierre C, Peyrat J, LouchePelisser C \& Laville M. A lipid-parameter-based index for estimating insulin sensitivity and identifying insulin resistance in healthy populations. Diabetes and Metabolism 200834 457-463.

8 Piché M-E, Weisnagel J, Corneau L, Nadeau A, Bergeron J \& Lemieux S. Contribution of abdominal viceral obesity and insulin resistance to cardiovascular risk profile of postmenopausal women. Diabetes $2005 \mathbf{5 4} 770-777$.

9 You T, Ryan A \& Nicklas B. The metabolic syndrome in obese postmenopausal women: relationship to body composition, visceral fat and inflammation. Journal of Clinical Endocrinology and Metabolism 200489 5517-5522.

10 Bastard JP, Vandernotte JM, Faraj M, Karelis AD, Messier L, Garrel D, Prud'homme D \& Rabasa-Lhoret R. Relationship between the hyperinsulinemic-euglycemic clamp and a new simple index assessing insulin sensitivity in overweight and obese postmenopausal women. Diabetes and Metabolism 200733 261-268.

11 Karelis AD, Faraj M, Bastard JP, St-Pierre D, Brochu M, Prud'homme D \& Rabasa-Lhoret R. The metabolically healthy, but obese individual presents a favorable inflammation profile. Journal of Clinical Endocrinology and Metabolism $2005 \mathbf{9 0}$ 4145-4150.

12 Faraj M, Messier L, Bastard JP, Tardif A, Godbout A, Prud'homme D \& Rabasa-Lhoret R. Apoprotein B: a predictor of inflammatory status in post-menopausal overweight and obese women. Diabetologia 200649 1637-1646.

13 Diamanti-Kandarakis E, Kouli C, Alexandraki K \& Spina G. Failure of mathematical indices to accurately assess insulin resistance in lean, overweight, or obese women with polycystic ovary syndrome. Journal of Clinical Endocrinology and Metabolism 2004 89 1273-1276.

14 Matthews DR, Hosker JP, Rudenski AS, Naylor BA, Treacher DF \& Turner RC. Homeostasis model assessment: insulin resistance and beta cell function from fasting plasma glucose and insulin concentrations in man. Diabetologia 198528 412-419.

15 Dawson B \& Trapp RG. Comparing correlations with variables in common in the same group coefficients. In Basic \& Clinical Biostatistics, edn 4, ch 8, pp 196-198. USA: Lange Medical Books/McGraw-Hill Companies Inc., 2004.

16 Abdul-Ghani MA, Matsuda M, Balas B \& DeFronzo RA. Muscle and liver insulin resistance indexes derived from the oral glucose tolerance test. Diabetes Care 200730 89-94.

17 Ferranini E \& Mari A. How to measure insulin sensitivity. Journal of Hypertension 199816 895-906.

18 Muniyappa R, Lee S, Chen H \& Quon M. Current approaches for insulin sensitivity and resistance in vivo: advantages, limitations, and appropriate usage. American Journal of Physiology. Endocrinology and Metabolism 2008294 E15-E26.

19 Katzuki A, Sumida Y, Gabazza E, Murashima S, Urakawa H, Morioka K, Kitagawa N, Tanaka T, Araki-Sasaki R, Hori Y, Nakatani K, Yano Y \& Adachi Y. QUICKI is useful for following improvements in insulin sensitivity after therapy in patients with type 2 diabetes mellitus. Journal of Clinical Endocrinology and Metabolism 200287 2906-2908.

20 Bastard JP, Jan V, Maachi M, Rabasa-Lhoret R, Jardel C, Bruckert E, Laville M \& Hainque B. Incorporation of nonesterified fatty acids into QUICKI is not relevant in obese subjects during diet inducing weight loss. Diabetes and Metabolism 200228 333-334.

21 Brunani A, Caumo A, Graci S, Margarini C, Viberti GC \& Liuzzi A. Revised vs original QUICKI index during diet + rosiglitazone treatment in obese subjects. Diabetes and Metabolism 200430 409-410.

22 Vaccaro O, Masulli M, Cuomo V, Albarosa Riveliese A, Uusitupa M, Vessby B, Hermansen K, Tapsell L \& Riccardi G. Comparative evaluation of simple indices of insulin resistance. Metabolism 200453 1522-1526.

23 Ijzerman RG, Stehouwer CD, Serné EH, Voordouw JJ, Smulders YM, Delemarre-van de Waal HA \& van Weissenbruch MM. Incorporation of the fasting free fatty acid concentration into quantitative insulin sensitivity check index improves its association with insulin sensitivity in adults, but not in children. European Journal of Endocrinology 2009160 59-64.

24 Abbasi F, McLauglhin T, Lamendola C \& Reaven GM. The relationship between glucose disposal in response to physiological hyperinsulinemia and basal glucose free fatty acid concentrations in healthy volunteers. Journal of Clinical Endocrinology and Metabolism 200085 1251-1254.

25 Krebs M, Stingl H, Nowotny P, Weghuber D, Bischof M, Waldhäusl W \& Roden M. Prevention of in vitro lipolysis by tetrahydrolipstatin. Clinical Chemistry 200046 950-954.

26 Kim SH, Abbasi F \& Reaven GM. Impact of degree of obesity on surrogate estimates of insulin resistance. Diabetes Care 200427 1998-2002.

27 Ruige JB, Mertens IL, Bartholomeeusen E, Dirinck E, Ferrannini E \& Van Gaal LF. Fasting-based estimates of insulin sensitivity in overweight and obesity: a critical appraisal. Obesity 200614 1250-1256.

28 Coon P, Rogus E, Drinkwater D, Muller D \& Goldberg A. Role of body fat distribution in the decline in insulin sensitivity and glucose tolerance with age. Journal of Clinical Endocrinology and Metabolism 199275 1125-1132.

29 Ozbey N, Sencer E, Molvalilar S \& Orhan Y. Body fat distribution and cardiovascular disease risk factors in pre- and postmenopausal obese women with similar BMI. Endocrine Journal 200249 503-509.

30 Lapointe A, Piché M-E, Weisnagel S, Bergeron J \& Lemieux S. Associations between circulating free fatty acids, visceral adipose tissue accumulation, and insulin sensitivity in postmenopausal women. Metabolism 200958 180-185.

31 Brochu M, Mathieu M-E, Karelis A, Doucet E, Lavoie M-E, Garrel D \& Rabasa-Lhoret R. Contribution of the lean body mass to insulin resistance in postmenopausal women with visceral obesity: a Monet Study. Obesity 200816 1085-1093.

Received 23 April 2009

Accepted 7 May 2009 